\title{
INFLUENCE OF THERMOPHYSICAL PROPERTIES OF CORES OF SELF-SHIELDING FLUX-CORED WIRES ON WELDING AND TECHNOLOGICAL PROPERTIES
}

\author{
A.S. KOTELCHUK \\ E.O. Paton Electric Welding Institute, NASU \\ 11 Kazimir Malevich Str., 03680, Kiev, Ukraine. E-mail: office@paton.kiev.ua
}

\begin{abstract}
In the paper the comparison of effectiveness of gas shielding of molten metal in welding with self-shielding fluxcored wires of carbonate-fluorite type was carried out considering the properties of their cores investigated by thermal analytical methods. It is shown that to improve reliability of gas shielding in welding using such wires it is important not only to ensure generation of large volume of shielding gases at thermal destruction of the wire core, but also to control this process, providing sufficient gas evolution at all stages of heating and melting of the wire. Using the data of differential scanning calorimetry of charge of the flux-cored wire of carbonate-fluorite type containing lithium carbonate, the evaluation of heat losses for heating and melting of powder core, accompanied by the development of energy-intensive processes of thermal destruction of core components, was carried out. It is proposed to limit the carbonate content in the wire at the level of 1-2\% of its weight, that allows keeping the values characterizing the stability of welding process at an acceptable level and, thus, providing a sufficient gas shielding of metal and good separation of slag crust. The control of thermochemical reactions in the core is achieved by selecting its necessary composition to ensure a favorable melting of flux-cored wire and electrode metal transfer to the weld pool. 5 Ref., 3 Tables, 5 Figures.
\end{abstract}

Keywords: arc welding, fux-cored wire, melting and metal transfer stability, thermal comprehensive analysis, thermophysical properties, welding and technological characteristics

Flux-cored wires for electric arc welding combine the advantages of two processes: welding using solid wire in shielding gases and manual arc welding with coated electrodes. As a rule, the flux-cored wires are composed of the components for alloying and deoxidation of weld metal, gas- and slag-forming components that provide protection of molten metal, its refining and the required chemical composition of weld metal, as well as easily ionizing additions, stabilizing the arc discharge to ensure a high efficiency of the process $[1,2]$.

The welding and technological properties of fluxcored wires determine the possibilities of their application for welding of different metal structures in various conditions, such as at the open areas exposed to wind (or uncontrollable air flows). These properties, in their turn, are mainly determined by the composition of flux-cored wires filler (core). The design of the composition of core allows controlling the processes of molten electrode metal transfer and its protection from exposure to the surrounding atmosphere (which is important, in particular, in using self-shielding fluxcored wires), as well as formation of weld metal and ensuring its required properties.
Self-shielding flux-cored wires represent a welding consumable, the application of which does not require shielding gas supply (for example, when performing welding and erection works, where the supply of shielding gas is complicated). In the self-shielding flux-cored wires of carbonate-fluorite type the protection of transferred molten electrode metal and weld pool from harmful interaction with oxygen and nitrogen of ambient air, that can lead to porosity and deterioration of mechanical properties of weld metal, is realized by thermochemical reactions of decomposition of carbonates and fluorine-silicates being components of the core of such wires, with the formation of protective atmosphere.

During welding under the site conditions, where the welding zone is inevitably exposed to uncontrollable air flows, there is a very urgent problem of reliability of molten metal protection. In this case, the effectiveness of protection in practice, as accepted, is evaluated as to the possibility of elongation of the arc $\Delta U_{\mathrm{a}}[2,3]:$

$$
\Delta U_{\mathrm{a}}=U_{\mathrm{a}}^{\max }-U_{\mathrm{a}}^{\min },
$$

where $U_{\mathrm{a}}^{\mathrm{min}}$ is the minimum arc voltage, at which welding for the preset current (electrode wire feed rate) is possible, and $U_{\mathrm{a}}^{\max }$ is the maximum arc voltage, at which it is possible to produce solid welds, i.e. the 
Table 1. Gas-forming composition of flux-cored wires

\begin{tabular}{|c|c|c|c|c|c|c|c|c|}
\hline \multirow{2}{*}{ Gas-forming components } & \multicolumn{9}{|c|}{ Content of components, wt.\% } \\
\cline { 2 - 11 } & \multicolumn{9}{|c|}{ In wire } & \multicolumn{5}{c|}{ In core } \\
\cline { 2 - 11 } & KF1 & KF2 & KF3 & KF4 & KF1 & KF2 & KF3 & KF4 \\
\hline $\mathrm{CaCO}_{3}$ & 2.8 & 2.6 & 3.7 & 3.9 & 16.1 & 16.2 & 22.4 & 21.2 \\
\hline $\mathrm{Na}_{2} \mathrm{CO}_{3}$ & 2.1 & 1.6 & - & 1.5 & 12.1 & 9.9 & - & 8.1 \\
\hline $\mathrm{Na}_{2} \mathrm{SiF}_{6}$ & - & 1.2 & 2.1 & 2.3 & - & 7.5 & 12.8 & 12.5 \\
\hline
\end{tabular}

welds where the pores caused by supersaturation of metal with nitrogen are absent.

Using the procedure described in work [3], the evaluation of resistance of the formed gas shielding in welding with self-shielding flux-cored wires of carbonate-fluorite type of $2.2 \mathrm{~mm}$ diameter against the effects of wind in the welding zone was carried out. The compositions of gas-forming part of cores of the wires are shown in Table 1.

As the slag-forming components fluorite $\left(\mathrm{CaF}_{2}\right)$, rutile $\left(\mathrm{TiO}_{2}\right)$, perovskite $\left(\mathrm{CaTiO}_{3}\right)$, wollastonite $\left(\mathrm{Ca}_{3}\left(\mathrm{Si}_{3} \mathrm{O}_{9}\right)\right)$ and alumina $\left(\mathrm{Al}_{2} \mathrm{O}_{3}\right)$ were also introduced to the wire core. Deposition of the reference beads on low-alloyed steel plates were carried out at welding current of $280 \mathrm{~A}$. All the four wires showed good shielding properties in welding under the influence of the wind flows in the zone of arcing at speed of up to $5 \mathrm{~m} / \mathrm{s}$. However, the deterioration in the efficiency of gas shielding of molten metal formed by them (reduction in the allowable elongation of the arc) with increase in wind speed higher than $5 \mathrm{~m} / \mathrm{s}$ is more noticeable in flux-cored wires KF1 and KF3 than in KF2 and KF4. The gas analysis of specimens, cut from the central part of the six-layer deposits, showed that with increasing the wind speed in the welding zone the nitrogen content in weld metal is increased, moreover,

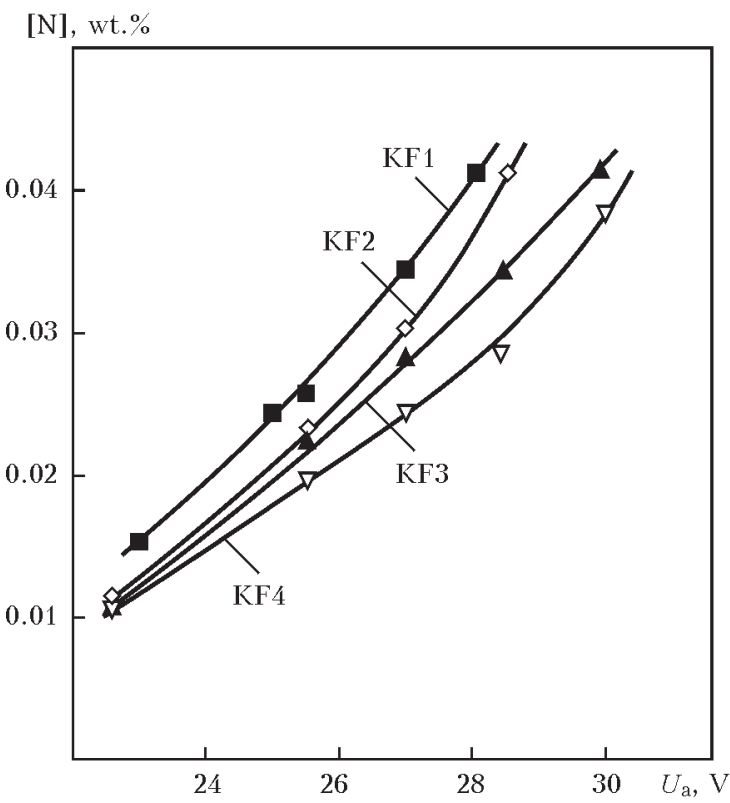

Figure 1. Effect of arc voltage on nitrogen content in metal deposited using flux-cored wires of carbonate-fluorite type the rate of increment of nitrogen content is comparable to the rate of narrowing the range of operating voltages at the arc (Figures 1 and 2).

The explanation for this fact can be found through investigation of thermophysical properties of models of wire cores at the dynamic heating to temperatures of about $1500{ }^{\circ} \mathrm{C}$, using the methods of complex thermal analysis, including thermal gravimetric, differential thermal gravimetric analysis and differential scanning calorimetry, as well as mass spectroscopy of the evolved gases [4].

Such investigations were conducted using combined thermal analyzer TGA/ DSC Q600 STD (TA Instruments, USA) and mass spectrometer VG ProLab (Thermo Scientific Fisher, Great Britain). Before conducting the investigations all the necessary calibrations of thermal analyzer were performed in accordance with the instructions: temperature, heat flow and mass signal in the entire investigated temperature range. The investigations were carried out in the $50 \mathrm{ml} /$ min air flow at linear heating rate of $10{ }^{\circ} \mathrm{C} / \mathrm{min}$. The mass of specimens in all the experiments was about $20 \mathrm{mg}$. For investigations ceramic crucibles (made of $\mathrm{Al}_{2} \mathrm{O}_{3}$ ) were used.

During thermal destruction of core materials the gases are evolved, different as to their molecular mass (in particular, $\mathrm{SiF}_{4}, \mathrm{CO}_{2}$ ), therefore, the data of thermal gravimetric analysis do not fully reflect the volumes of the evolved shielding gases. As far as 1 mole of any gas at the identical conditions (pressure and temperature) occupies the same volume, then it seems

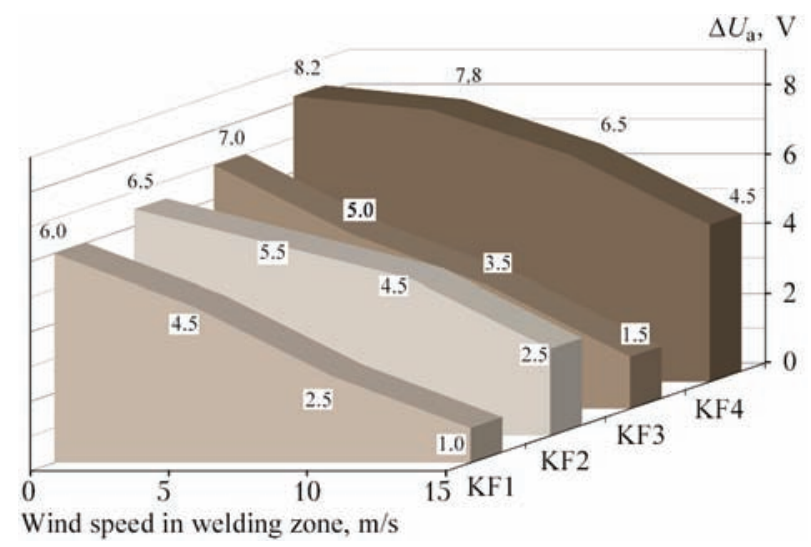

Figure 2. Possibility of arc elongation $\Delta U_{\mathrm{a}}=\Delta U_{\mathrm{a}}^{\max }-\Delta U_{\mathrm{a}}^{\min }$ during welding using self-shielding flux-cored wires of carbonate-fluorite type exposed to wind flow 
$\left\{\mathrm{CO}_{2}\right\}+\left\{\mathrm{SiF}_{4}\right\}, 1$ mole per $1 \mathrm{~g}$ of wire

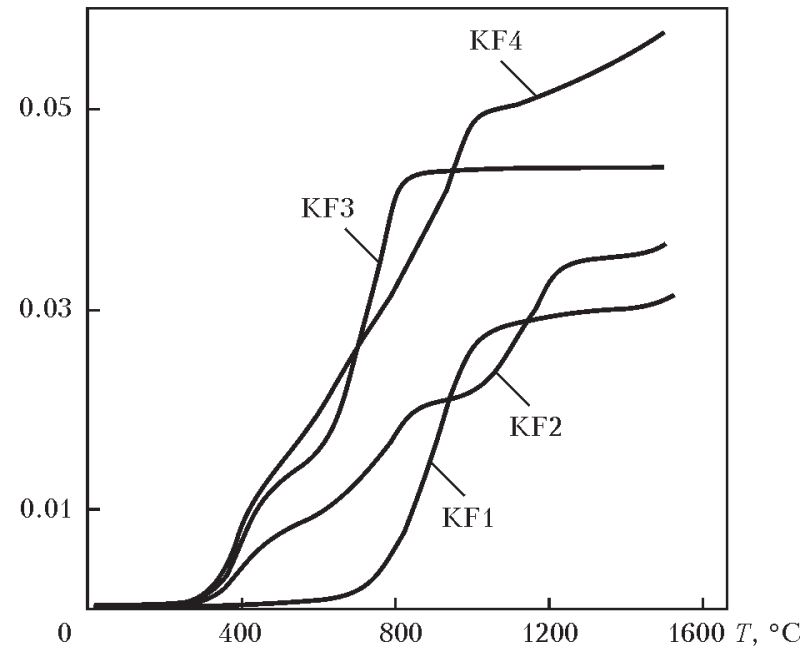

Figure 3. Total amount of shielding gases $\left(\mathrm{CO}_{2}, \mathrm{SiF}_{4}\right)$ evolved from the cores of flux-cored wires of carbonate-fluorite type at continuous heating at $10{ }^{\circ} \mathrm{C} / \mathrm{min}$ rate of $1 \mathrm{~g}$ of flux-cored wire

to be rational to evaluate the formation of gas shielding during thermal destruction of core components of flux-cored wire in molar volumes. During calculations of molar volume of shielding gases the compositions of wires were taken into account. The data on temperature dependences of molar amounts of shielding gases formation, referred to the mass of wire, are shown in Figure 3. These data can confirm that shielding properties of flux-cored wire composition during welding in the absence of external influence of air flows on the welding zone directly depend on the volume of shielding gases formed during heating and melting of core.

So, the best characteristics of the four considered wires are provided by the composition of wire KF4, and the worst - by KF1. But this approach cannot explain the difference in composition shielding characteristics of wires KF3 and KF2 during welding under the influence of air flows. At speed of air flow higher than $5 \mathrm{~m} / \mathrm{s}$, wire KF2 is characterized by a more stable

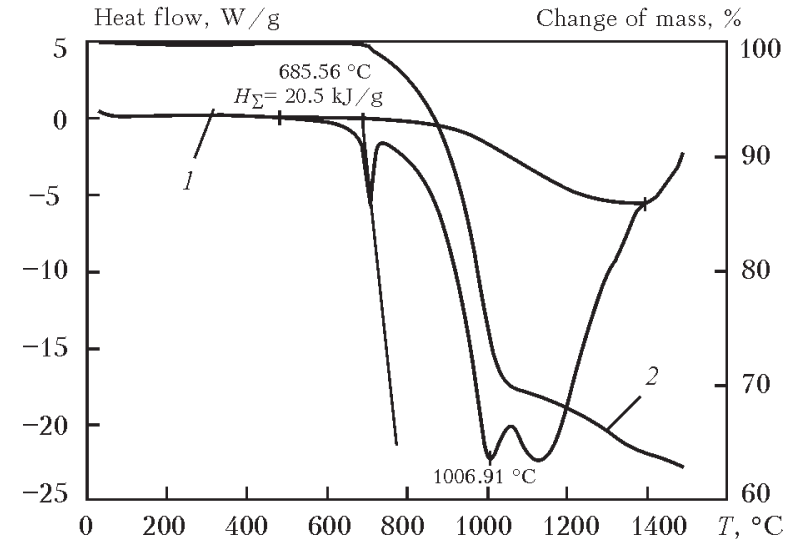

Figure 4. Thermal analysis of model charge of flux-cored wire, containing $\mathrm{Li}_{2} \mathrm{CO}_{3}$, using methods of differential scanning calorimetry and thermal gravimetry: 1 - heat flow; 2 - change of mass protection to the effects of wind than $\mathrm{KF}$, although the volume of shielding gases formed during heating and melting of the KF3 core is higher than that of KF2. The formation of protective atmosphere during heating the charge of KF3 occurs in a comparatively narrow temperature range.

Considering the quasi-steady state of temperature distribution during heating of flux-cored wire at the stickout, it results in narrowing the sizes of gas formation zone in the stickout. The bulk of shielding gases for the KF1 core (over 75 wt.\%) is evolved in the temperature range from 600 to $800{ }^{\circ} \mathrm{C}$, and the whole process of gas formation is completed already before reaching $900{ }^{\circ} \mathrm{C}$. For the KF2 charge a more uniform distribution of shielding gases $\left(\mathrm{CO}_{2}\right.$ and $\left.\mathrm{SiF}_{4}\right)$ is characteristic in the temperature range from 400 to $1400{ }^{\circ} \mathrm{C}$, that is predetermined by using a mixture of carbonates and a higher share of fluxes in the charge. Before melt is formed in the charge composition, sodium carbonate facilitates the beginning of dissociation reaction of calcium carbonate, and after formation of the melt it inhibits the evolution of shielding gases (see Figure 3).

Thus, the obtained data evidence that to ensure the high efficiency of gas shielding during welding with self-shielding flux-cored wires it is important not only to ensure the generation of a large amount of shielding gases, but also to control the processes of gas evolution to create a protective atmosphere at all stages of heating and melting of the flux-cored wire, electrode metal transfer and weld pool formation.

The heat losses for heating and melting of powder core can significantly affect the welding and technological properties of the flux-cored wire [1]. The evaluation of these losses can be carried out using the data of differential scanning calorimetry on the example of charges of flux-cored wires of carbonate-fluorite type containing lithium carbonate (Figure 4). During heating the model charge of flux-cored wire the heat is consumed on melting and thermal dissociation of $\mathrm{Li}_{2} \mathrm{CO}_{3}$ leading to formation of $\mathrm{Li}_{2} \mathrm{O}$ in the slag phase and evolution of $\mathrm{CO}_{2}$ gas phase. Moreover, the total thermal effect $H_{\Sigma}$ (see Figure 4) can reach $20.5 \mathrm{~kJ} / \mathrm{g}$ of the model core.

These data allow evaluating the heat balance during heating and melting of flux-cored wire, the core of which contains lithium carbonate. Thus, for example, in welding using flux-cored wire of $1.6 \mathrm{~mm}$ diameter, containing 1 wt. $\%$ of $\mathrm{Li}_{2} \mathrm{CO}_{3}$, at $U_{\mathrm{a}} \approx 24 \mathrm{~V}$ and $I_{\mathrm{w}} \approx 250 \mathrm{~A}\left(v_{\mathrm{w} . \mathrm{f}} \approx 3.5 \mathrm{~m} / \mathrm{min}\right)$ up to $2.4 \%$ of input energy will be consumed for heating, melting and thermal dissociation of core components, resulting in a noticeable deterioration of welding and technologi- 
Table 2. Statistical data on welding process using pilot self-shielding flux-cored wires

\begin{tabular}{|c|c|c|c|c|c|c|c|c|}
\hline \multirow[b]{2}{*}{$\begin{array}{c}\mathrm{Li}_{2} \mathrm{CO}_{3} \text { content } \\
\text { in wire, wt. } \%\end{array}$} & \multicolumn{3}{|c|}{ Arc voltage } & \multicolumn{3}{|c|}{ Welding current } & \multirow[b]{2}{*}{$\begin{array}{c}\text { Short-circuit } \\
\text { average time, } \mu \mathrm{s}\end{array}$} & \multirow{2}{*}{$\begin{array}{c}\text { Frequency } \\
\text { of short- } \\
\text { circuits, s }\end{array}$} \\
\hline & $\begin{array}{c}\text { Mean } \\
\text { value, } \mathrm{V}\end{array}$ & $\begin{array}{c}\text { Standard } \\
\text { deviation, V }\end{array}$ & $\begin{array}{c}\text { Variation } \\
\text { coefficient }\end{array}$ & $\begin{array}{c}\text { Mean } \\
\text { value, } \mathrm{A}\end{array}$ & $\begin{array}{c}\text { Standard } \\
\text { deviation, A }\end{array}$ & $\begin{array}{c}\text { Variation } \\
\text { coefficient }\end{array}$ & & \\
\hline 0 & 23.1 & 2.3 & 0.10 & 289.1 & 28.0 & 0.10 & 112.5 & 4 \\
\hline 1 & 21.8 & 1.6 & 0.07 & 296.4 & 24.9 & 0.08 & 159.7 & 15 \\
\hline 2 & 22.9 & 2.4 & 0.10 & 283.0 & 36.0 & 0.15 & 225.0 & 26 \\
\hline 3 & 22.0 & 3.8 & 0.17 & 294.5 & 49.4 & 0.17 & 532.0 & 75 \\
\hline
\end{tabular}

Table 3. Values of technological properties of flux-cored wires containing different amounts of carbonates in the core

\begin{tabular}{|c|c|c|c|c|c|}
\hline $\begin{array}{c}\mathrm{Li}_{2} \mathrm{CO}_{3} \text { content } \\
\text { in wire, wt. } \%\end{array}$ & Arc voltage, $\mathrm{V}$ & Welding current, A & $\begin{array}{c}\text { Losses } \\
\text { for spattering, } \%\end{array}$ & $\begin{array}{c}\text { Separation } \\
\text { of slag crust, } \\
\text { point }\end{array}$ & $\begin{array}{l}\text { Presence } \\
\text { of defects }\end{array}$ \\
\hline 0 & $\begin{array}{l}19-22 \\
23-26\end{array}$ & $\begin{array}{l}220-270 \\
250-300\end{array}$ & $\begin{array}{l}5.1 \\
4.8\end{array}$ & $\begin{array}{l}3 \\
3\end{array}$ & $\begin{array}{c}\text { No } \\
\text { Pores }\end{array}$ \\
\hline 1 & $\begin{array}{l}19-22 \\
23-26\end{array}$ & $\begin{array}{l}220-250 \\
250-300\end{array}$ & $\begin{array}{l}5.2 \\
4.9\end{array}$ & $\begin{array}{l}5 \\
5\end{array}$ & $\begin{array}{l}\text { No } \\
\text { Same }\end{array}$ \\
\hline 2 & $\begin{array}{l}19-22 \\
23-27\end{array}$ & $\begin{array}{l}250-300 \\
310-350\end{array}$ & $\begin{array}{l}7.2 \\
6.9 \\
\end{array}$ & $\begin{array}{l}5 \\
5\end{array}$ & $"$ \\
\hline 3 & $\begin{array}{l}18-22 \\
22-24 \\
\end{array}$ & $\begin{array}{l}240-290 \\
300-350 \\
\end{array}$ & $\begin{array}{c}11.3 \\
9.3 \\
\end{array}$ & $\begin{array}{l}4 \\
4 \\
\end{array}$ & $"$ \\
\hline
\end{tabular}

cal properties, i.e. decrease in stability of the arc and increased spattering of the electrode metal.

The evaluation of welding and technological properties of self-shielding flux-cored wire with different content of lithium carbonate in the core was carried out on the example of $1.6 \mathrm{~mm}$ diameter wire of a tubular design. Welding was carried out at direct current of straight polarity. The results of statistical processing of the values of current and voltage of arc welding using these flux-cored wires obtained applying the system with high-speed analog-to-digital converters for monitoring and processing of electrical signals of arc welding at frequency of $50 \mathrm{kHz}$ [5], are shown in Table 2 and Figure 5.

The obtained data show that the content of lithium carbonate in the wire core does not affect the technological characteristics of the process significantly, when its content amounts up to $2 \%$ of wire mass. The exceeding of this value leads to increased spattering of the electrode metal (Table 3).

In general case, the introduction of carbonates facilitates the improvement of separation of slag at the edges of weld metal. This improvement is explained by the influence of oxides, formed during decomposition of carbonates, on homogenization of the slag. The increase in the content of carbonates in the wire core to higher than $2 \mathrm{wt} . \%$ does not improve the gas shielding significantly, but leads to significant changes in the chemical composition of the weld metal, i.e. to somewhat reduced content of deoxidizing and alloying elements in the weld metal, and the oxygen content increases.

Thus, it can be concluded that it is rational to limit the carbonate content in the wire at level of $1-2 \%$ of its mass, that allows preserving the values, characterizing the stability of welding process at the acceptable level, and providing effective gas shielding of metal and good separation of slag crust.

In conclusion it should be noted that investigations of physical and chemical properties of powder materials and their mixtures, which model the cores of fluxcored wires, carried out using the methods of complex thermal analysis (differential thermal, thermal gravimetric, differential thermal gravimetric analysis and scanning calorimetry), as well as the method of mass spectroscopy of gas phase during dynamic heating up to the melting point of steel, showed that the process of heating the mixtures of the powder materials, containing gas- and slag-forming components together with metal powders, is accompanied by proceeding of dissociation reactions with gas evolution, oxidation,

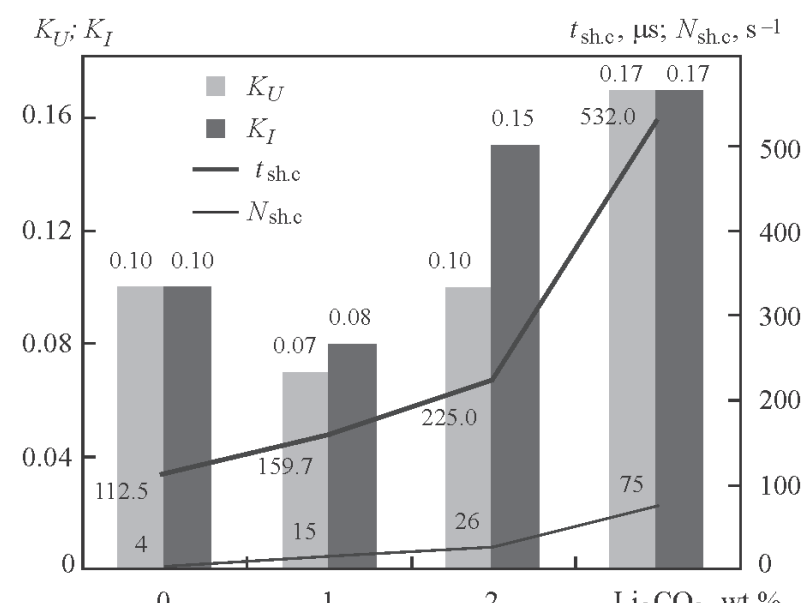

Figure 5. Variation coefficients of arc voltage $K_{U}$ and welding current $K_{I}$, average time $t_{\text {sh.c }}$ and frequency $N_{\text {sh.c }}$ of short circuits in welding using pilot self-shielding flux-cored wires depending on lithium carbonate content in the wire core 
melting of mixtures and formation of primary melt of metal and slag phases. The formation of slag melt already at the stage of heating the powder core before melting of the wire sheath and evolution of gases $\left(\mathrm{CO}_{2}, \mathrm{SiF}_{4}\right)$ facilitates the improvement of shielding features of flux-cored wires in welding without additional protection. The thermal effects of thermochemical reactions, which accompany the process of heating, run simultaneously (endothermal processes of destruction, melting and exothermal oxidations and formations of complex compounds). The control of these reactions due to the changes in the mixture composition allows regulating the rate of core melting, facilitates the formation of favorable characteristics of flux-cored wire melting and electrode metal transfer to the weld pool.

As the components of flux-cored wire, which reduce the temperature of beginning of fusion of the core, it is rational to use the metal powders based on aluminum and its alloys, non-metallic slag- and gasforming components such as carbonates, oxides and fluorides of alkali metals.

1. Widgery, D. (2005) Tubular cored wire welding. In: New developments in advanced welding, 21-39. Cambridge: Woodhead Publ.

2. Pokhodnya, I.K., Yavdoshchin, I.R., Shvachko, V.I. et al. (2004) Metallurgy of arc welding. Interaction of gases with metals. Ed. by I.K. Pokhodnya. Kiev: Naukova Dumka.

3. Shlepakov, V.N., Suprun, S.A., Kotelchuk, A.S. (1990) Estimating of the characteristics of flux-cored wire welding under the wind flow effect. In: Proc. of Int. Conf. on Welding under Extreme Conditions (Helsinki, Finland, 4-5 Sept., 1989), 171-179. N.Y.: Pergamon Press.

4. Shlepakov, V.N., Kotelchuk, A.S. (2011) Investigation of thermochemical characteristics of mixtures of dispersed materials by differential thermal analysis methods. The Paton Welding J., 12, 13-16.

5. Ponomarev, V., Al-Erhayem, O., Apps, R.L. et al. (1997) Arc welding process statistical analysis. Methodical approaches, analysis conceptions, experiences: Manual-guide. DTUHelsingor: JOM-Institute. 